Dr Guy Fielding (CPsychol, AFBPS)

is a chartered social psychologist who has been researching, teaching and providing consultancy in the fields of interpersonal and organisational communication for 25 years. As an academic, he was closely involved in the development of communication studies as a discipline in the $U K$, becoming head of the Department of Communication and Information Studies at Edinburgh's Queen Margaret College in 1991 before joining the faculty of the University of Oxford's Department of Experimental Psychology in 1997. Now director of research and development for $C M$ Insight, a Weybridge, UKbased customer contact consultancy, he is involved in the application of properly grounded theory and research to the design and implementation of customer contact strategies for a wide range of leading $U K$ and international organisations.

Keywords: call centres, customer contact strategy, communication quality, conversational competence, performance metrics, branded conversation

Guy Fielding

CM-Insight

The Old Warehouse

Church Street

Weybridge

Surrey KT13 8DG, UK

Tel: +44 (0)1932 268100

Fax: +44 (0)1932 268109

E-mail: Guy.Fielding@cm-

insight.com

\section{Taking conversation seriously: The role of the call centre in the organisation's customer contact strategy}

\author{
Guy Fielding \\ Received (in revised form): 11 November 2002
}

\begin{abstract}
This paper argues that the traditional role of call centres fails to understand and properly exploit this customer contact channel which potentially offers an extremely attractive set of communication characteristics. Instead, call centres have largely negative associations for customers, companies and agents.

The ultimate cause of this is identified as a misunderstanding of what constitutes good communication. This has led to errors in the design, operation and management of the typical call centre. Inadequate attention paid to the conversations agents have with customers means that these conversations are rarely monitored or managed effectively. A practical methodology based on extensive empirical and theoretical communication research is outlined, and its use for the analysis and evaluation of conversations is described.

The call centre's potential is explored by showing how an organisation's brand values can be translated into conversational behaviours. The call centre can then become a primary element in an organisation's marketing strategy. Companies invest heavily in brands but fail to extend their implementation beyond the visual media into the conversations they have with their customers. These conversations are then at best 'brand neutral', and at worst 'brand destructive'. They are rarely 'brand building'.

The practical steps needed to deliver the 'brand in conversation' are described, and some of the implications of these ideas for the changing role of call centres, and for the concept of brand, are discussed.
\end{abstract}

\section{Introduction: The contact centre context}

The call centre, or in its most recent incarnation the contact centre, is a ubiquitous feature of modern life. It is difficult to imagine a moderate to large-sized business operating in either the business-to-consumer or business-to-business market which does not offer its customers the ability to contact it via the telephone and other electronic channels, and which does not organise the handling of these contacts by means of an in-house and/or outsourced contact centre. There are currently (autumn 2002) some 150,000 call centres worldwide, located in every continent except Antarctica. They employ 3 per cent of the North American workforce, 1.6 


\section{Phone is low cost, high effectiveness}

per cent of the European workforce and some 2 per cent of the UK workforce. ${ }^{1}$ In the UK in 2002 there are 5,700 call centres employing 384,000 agents, with these figures predicted to increase by over 20 per cent over the next five years, to 470,000 agents and 6,900 contact centres, constituting over 3 per cent of the UK working population. ${ }^{2}$ The importance of the contact centre to the modern business is indicated by the scale of the operation. For instance, in 2002 the retail division of just one company, BT, operates some 135 separate call centres and on average handles 2.3 million contacts with customers each working day.

In these terms the call centre has been an enormous success, and its success has been a key feature of the way that modern companies conduct their businesses. For most businesses the call centre operation is an essential feature of their customer service strategy. For many it has radically transformed the way that the business operates and, in some cases, the products and services that the business offers. For a significant number of businesses, such as First Direct and Direct Line in the UK, the call centre $i s$ the business. Contact centres offer, relative to other channels of customer interaction, an attractive set of features. As a communication channel they offer two-way one-to-one interaction rather than the undifferentiated one-way mass communication of advertising, brochures or a website. They also offer real-time (synchronous) communication rather than the asynchronous communication offered by letters or e-mail. Call centres also use the richest of all human communication codes: natural language and the associated paralinguistics. This 'rich' channel allows conversations of considerable variety and complexity that can encompass not only the task and informational components of a conversation, but also the social relationship and personal-emotional aspects. Organisationally, call centres offer a relatively low-cost, relatively easily managed facility that can be scaled in size, reach and time to provide $24 / 7$ service to large customer bases across large geographical areas. For the customer they offer high levels of access at minimal costs to well-trained and properly supported staff at times and locations that are most convenient to the customer.

The paradox is that for almost all the people involved in the operation of call centres, they have a very poor reputation. For customers they are believed to provide a negative experience, for the agents they are 'the sweatshops of the 21 st century' and for companies they are a major consumer of costs and resources. Why has the potential of the call centre not been fully realised?

\section{Current approaches to contact centre management}

One important answer to this paradox is to examine the current management of call centres. It is a truism to note that 'managers manage what they can measure'. Current approaches to managing performance and quality in contact centres have evolved in conjunction with and, it might be argued, in response to the available tools. The technologies that have become de facto standards in the modern-day contact centre have determined what information is easily available to modern managers. In 
turn, this has determined the aspects of performance and quality that are actively managed.

De facto technologies include:

- ACDs (automatic call distribution, or the 'switchboard' for inbound calls)

- power/predictive diallers (automatic pre-dialling of calls, or the 'switchboard' for outgoing calls)

- databases, CRM systems and management information systems (these record customer and product/service information and related transactions)

- CTI (computer-telephone integration).

\section{Technologies drive measurement and management}

\section{Quantity not quality}

\section{Even good scripts are poor conversations}

The availability and pervasiveness of these technologies naturally lead managers to focus on the measures readily recorded by them. These tend to be about the quantity of demand, activity and output, such as:

- average time to answer

- average call length

- calls per agent per hour

- decision-maker contacts per hour.

These mechanistic productivity measures focus on the quantity of tasks being completed rather than their quality, in large part because quality is considered to be harder to define and measure, and certainly difficult if not impossible to monitor mechanically or electronically. Managers are measuring, and managing, what it is easiest to measure, not necessarily what it is important to measure.

All of this has led to a focus on productivity targets that can be easily measured and, therefore, targeted and incentivised. It is hardly surprising that, in such an environment, concern with the quality of the interaction appears to be less important and is given less priority by both managers and agents. Indeed, in some organisations there is assumed to be a negative relationship between a concern with quantity (productivity) and a concern with quality. In a cost-driven environment, 'doing more' is more important than 'doing it well'.

If, in these environments, so-called 'quality standards' are in place, they appear to be implemented as a safety net to ensure that, during the drive for throughput, the quality of the task performance does not fall below the absolutely lowest acceptable level, such as failing to meet external standards for compliance. Quality is then reduced to a negative, concerned with the absence of problems rather than with making a positive contribution to the achievement of the organisation's goals.

The use of scripts within contact centres illustrates this kind of approach. Rather than a positive drive to produce skilled conversations, adapted to the particularities and circumstances of the individual customer, a script is designed to ensure that every conversation at least conforms to an acceptable norm. However, a fundamental characteristic of good communication is that it is appropriate, and this means that the 


\section{Mechanistic models misapplied to human communication}

form of each and every conversation must to a greater or lesser extent vary as a function of the particular characteristics of the communication. As such, scripted conversations cannot be quality conversations.

\section{Defining (good) communication}

Although the practicalities of measurement are to some extent to blame for the current approach to call centre metrics, another associated reason is the predominant model of communication. This is illustrated by the following dictionary definition:

'1. communications The act of communicating; transmission.

2. communications The exchange of thoughts, messages, or information, as by speech, signals, writing, or behaviour.

3. communications (used with a sing. or pl. verb) a. The art and technique of using words effectively to impart information or ideas. $\mathbf{b}$. The field of study concerned with the transmission of information by various means, such as print or broadcasting. c. Any of various professions involved with the transmission of information, such as advertising, broadcasting, or journalism.

4. communications Something communicated; a message.

5. communications A means of communicating, especially: a. A system, such as mail, telephone, or television, for sending and receiving messages. b. A network of routes for sending messages and transporting troops and supplies.

6. communications The technology employed in transmitting messages. ${ }^{3}$

This typical dictionary definition indicates the predominant model of communication as a process fundamentally concerned with the transfer of information. It in turn is derived from and aligned to the ShannonWeaver ${ }^{4}$ model of communication, and of information theory which was associated with it. The problem is that these models were not intended as, and are not very good, models of human communication. They were created in order to understand and manage non-human systems (in fact, telephone systems). Contact centres deal with human communication, and the primary purpose is to establish commonalities and to create the basis for coordinated action. In the human context the emphasis is less on the accuracy and efficiency of information transmission, and more to do with the establishment of identity and relationships on which future coordinated action can be based.

The following alternative definition of human communication can be offered: 'The attempt by two or more people to establish, maintain and develop the basis for coordinated action.'

\section{Describing good communication}

Accurate information transfer is only one aspect of good communication, others include:

- encounter regulation

— identity management 


\section{Communication is not just information exchange}

\section{What is needed for good conversation}

— management of roles and relationships

— instrumental control

- performative exchange

- emotional management

- aesthetic management

- meta-communicative regulation

- management of conversational norms.

A conversation that only involved the transfer of information would be most unusual (if not impossible), and would sound as though it were taking place between machines rather than human beings. It would be unlikely to be described by anyone as 'good' conversation.

Although this alternative model of communication is more complex, it is also a view of communication which acknowledges the kind of communication that human beings are best at. Indeed, a variety of disciplines have provided evidence that human beings are uniquely adapted and are uniquely good at communication, particularly the use of language to communicate, and the use of communication in order to coordinate and cooperate. In particular, studies of communication competence, ${ }^{5}$ social skills ${ }^{6}$ and communication style ${ }^{7}$ have analysed the components required to create high-quality communication between individuals.

\section{The components of good communication}

From this research it is possible to identify a list of key conversational skills:

— speaking activity

- listening activity

- interpretive understanding

- adaptive competence

- task competence

- communication confidence

- emotional competence

— personal involvement

— politeness

- rewardingness.

\section{Speaking activity}

A good conversation requires each participant to contribute an appropriate amount of talk. But talking enough is only the start. Each contribution to the conversation must come at the right time; being microsynthesised to the rhythm and pattern of the conversation and macrosynthesised to the content and purpose of the conversation. Speaking activity must also be appropriate in terms of energy level; gentle and quiet in some circumstances, quick and loud in others.

\section{Listening activity}

To listen well is to be actively involved in the creation of good conversation. Good listeners signal their involvement and interest to the 
speaker by using unobtrusive verbal and non-verbal signals that support, encourage and guide the speaker. Active listeners will ask questions and make reflections, providing feedback on the effect of what is being said.

\section{Interpretive understanding}

Listening provides the raw material for interpretive understanding; understanding what is being communicated even when it is not explicitly said. Honing this skill involves thinking carefully about the implications of what is being said and what is not being said, and relating it to what was said before.

\section{Adaptive competence}

The ability to adapt to the needs of other participants is a prerequisite of good conversation. Information must be imparted in ways that make sense to the listener. That means providing appropriate information, in appropriate quantities and at an appropriate level of detail. The information provided needs to be relevant, well structured, coherent and connected. Doctors, for example, will speak differently about their patients' conditions if they are speaking to the patient themselves or to a colleague.

\section{Task competence}

Though talk for talk's sake is a much under-rated activity, many conversations have a purpose to fulfil. Participants need to know what they are talking about, to be knowledgeable about the issues and tasks they are discussing.

\section{Communication confidence}

When deciding whether or not to act on the information provided by other people, people not only consider its intrinsic merits, but also look for clues in terms of the characteristics of the source of the information. One of the most important of these characteristics, particularly when dealing with strangers, is whether or not they 'sound as if they know what they are talking about'; in other words, their 'expressed confidence'. When the speaker sounds relaxed and confident, is fluent rather than hesitant and expresses certainty rather than doubt, they are more likely to be believed.

\section{Emotional competence}

A good conversationalist is sensitive to the other person's emotional state and will acknowledge and respond to it appropriately. They will, for example, sympathise if the person is sad or distressed. Responding to the other person's emotions in ways that allow them to manage their own emotions productively is a valuable skill.

\section{Personal involvement}

For a good conversation both participants have to 'be there'. When the participants are involved, open and approachable, then the conversation, even if businesslike and action oriented, is more likely to be successful than if they are distant and detached. 


\section{Model plus methodology needed to assess conversation}

\section{Generic vs specific conversation quality}

\section{Politeness}

People taking part in conversation need to take care of the other participants. This process is referred to as 'politeness', and much of it is routine and ritualised. Politeness extends beyond routines such as saying 'hello' and 'goodbye'; it also includes courtesy, tact and sensitivity maintained throughout the conversation. When it happens it is barely noticed; when it does not it is very noticeable.

\section{Rewardingness}

Politeness might be referred to as passive or reactive positiveness. Rewardingness refers to the way in which people can make conversation proactively positive. Such conversation is positive in tone, facilitating, encouraging, supportive and friendly.

\section{Assessing communication quality}

These dimensions of competent communication can be used to evaluate all kinds of human communication, including calls to and from agents in call centres. In addition to this theoretically based model of communication competence, the following processes are needed to allow an accurate, reliable and usable assessment of the quality of communication produced by any given call centre.

- Use of a statistically robust and significant sampling procedure to select real (rather than staged) calls for analysis. (In practice, sampling theory shows that a random sample of approximately 400 calls provides an accuracy of $+/-5$ per cent largely independent of the total call volumes being handled.)

- Recording and retrieval of real calls systematically and unobtrusively (in order to avoid reactive observation effects impacting on the behaviour of either the agent or the customer).

- Use of independent, trained raters to provide objective and reliable evaluation of the calls, together with appropriate quality assessment and standardisation procedures in order to determine and control for inter-rater reliability.

- Use of appropriate statistical analyses to determine the significance and power of any differences and relationships that are identified within the data.

- An interpretation of the statistical analyses based on an understanding of call centre operations and business objectives, so as to derive practical interventions to improve conversational quality.

\section{Differentiating communication quality}

The preceding description of communication and customer conversations has been based on what might be described as a 'generic' understanding of the meaning of quality with respect to communication. However, it is possible to identify two distinct aspects of quality:

- 'quality' in the sense of 'fitness for purpose'; that is the evaluation of the experience (was it 'good' or 'bad'?) 


\section{Brand is more than image}

- 'quality' in the sense of the particularities or distinctiveness of the experience (for instance, it is this sense of quality that we use when talking about a person's qualities, and it is these qualities that give them a distinctive identity or personality).

In an environment in which goods and services are becoming commoditised, companies must seek market differentiation on the basis of the service experience they provide to customers. If organisations fail to differentiate themselves in terms of the experience they offer to customers, then they must expect that customers will form their own basis for differentiation, and, in the default, this is likely to be with respect to price. Increasingly companies must create a service experience that is allencompassing, unique and compelling. This is clearly concerned with more than just conversation; it involves every element of the product or service and the way it is offered and delivered. However, conversation, the way the company behaves when it interacts with the customer, is central. Psychological research has repeatedly shown that a direct behavioural experience, such as a conversation with a contact centre agent, has the greatest permanent impact on people's attitudes and behaviour.

\section{Distinctive conversations and brand fidelity}

The conversations that take place between organisations and their customers are a major component of the customer experience and a key determinant of its quality. However, although organisations spend substantially on defining their brand and then developing a distinctive image that is applied consistently across their visual communications, few apply the same logic and implementation to verbal communication or seek to create brand-aligned conversations with customers. Translating an organisation's stated brand values into conversational behaviours and styles allows customer-facing staff to 'live' the brand and present it in their dealings with customers. Brand-aligned conversations create familiarity, because they are consistent with the customer's whole experience of the organisation and differentiated because they are unlike conversations the customer has with other organisations.

These two senses of quality, of being 'good' and of being 'differentiated', come together when considering communication quality in the call centre, linked by the notion of brand fidelity. As noted above, at the heart of good communication is the notion of appropriateness and adaptiveness. Good communication varies depending on who the agent is talking with, what they are talking about and why, and when and where the conversation is taking place. To allow agents to produce quality conversations it is therefore necessary to allow them to vary what they say and how they say it. However, no organisation would wish to allow its agents to say whatever they liked. Organisations must find ways to allow agents to have freedom and flexibility, but in ways that are managed and manageable.

The notion of 'brand in conversation' is the key to this dilemma. The agents' understanding of the brand they represent, and the limits and possibilities that the brand identity presents for what can and cannot be 


\section{Understanding the brand generates good conversation}

\section{Empowering the agent to deliver 'brand in conversation'}

\section{'Brand in conversation' changes call centres} $\cdots$

\section{... call centres change brands}

said, allow the agents to produce conversations that are different every time and yet essentially the same: different because each is adapted and appropriate to the specific individual customer; the same because each is imbued with the brand values of the organisation.

In the same way that it is possible to operationalise and measure the generic evaluative quality of a conversation, so it is possible and necessary to measure the degree to which the conversation represents and embodies the brand identity of the organisation. On the basis of this process of measurement it is then possible to manage actively the brand fidelity of the conversations produced by the call centre, with the call centre becoming an active element in the stewardship and promotion of the brand to the customer.

\section{Implementing the 'brand in conversation'}

Implementing the 'brand in conversation' involves many of the same steps that are involved in the conventional visual implementation of the brand. However, in practice many of the disciplines are unfamiliar and apparently esoteric. While most people are familiar with the notion of a graphic designer or image consultant, the idea of a 'conversational designer' being involved in the development of a brand is unusual and exotic. Perhaps the most interesting and important aspects of this process are, however, in the implementation rather than the design stage. To implement the 'brand in conversation' it is necessary for call centre agents really to understand the brand, and to have internalised this understanding so that it can guide their interactions with customers in real time. This means that agents must be involved on an ongoing basis with the brand and become the prime guardians and promoters of the brand for the company. To do this they need to be supported in a variety of ways by their managers and by the organisation, for instance in terms of the metrics and incentives for recognition and reward.

The recognition of the importance and potential of taking conversation seriously, and promoting the centrality of good communication to firstclass customer service, is likely to have a number of other, longer-term and more profound effects. The first of these is that it is likely to add to the increasing recognition by organisations that the customer interaction and relationship is their primary differentiator and source of competitive advantage. Associated with this there is likely to be a change in the role and status of the call centre, and of call centre staff within the organisation. Rather than being seen as of low status and ability, and incidental to the core activities of the organisation, the call centre is more likely to be seen as at the heart of the organisation, and as requiring highly skilled staff with long-term commitment to the organisation and its brand, who must be trained, supported and compensated accordingly. Finally, if the conversations created by the organisation are seen as an important and integral part of the brand, then this is likely to lead to a profound change in the understanding of what a brand is. Rather than being a promise that may or may not be fulfilled, the brand in conversation is something that represents what the organisation really is 
when dealing with its customers. The brand will then become an encapsulation of 'who we are and how we do things'.

\section{References}

1. The Week (2002) 'The voice at the end of the telephone', 24 August, p. 11.

2. Datamonitor (2002) 'Call centres in EMEA to 2007', Datamonitor Reports, DMTC 085202, October.

3. American Heritage Dictionary of the English Language (2002) 4th edn, Houghton Mifflin, Boston.

4. Shannon, C. E. and Weaver, W. (1949) The Mathematical Theory of Communication, University of Illinois Press, Urbana, IL.

5. Spitzberg, B. H. and Cupach, W. R. (1989) Handbook of Interpersonal Communication Research, Springer-Verlag, New York; Parks, M. R. (1994) 'Communicative Competence and Interpersonal Control', in Knapp, M. L. and Miller, G. R. (eds) Handbook of Interpersonal Communication, 2nd edn, Sage, Thousand Oaks.

6. Argyle, M. (1994) The Psychology of Interpersonal Behaviour, 5th edn, Penguin, London; Hargie, D. W. (ed.) (1997) The Handbook of Communication Skills, 2nd edn, Routledge, London.

7. Norton, R. (1983) Communicator Style, Sage, Beverly Hills; Giles, H. and Street, R. L. (1994) 'Communicator Characteristics and Behaviour', in Knapp and Miller, ref. 5 above. 